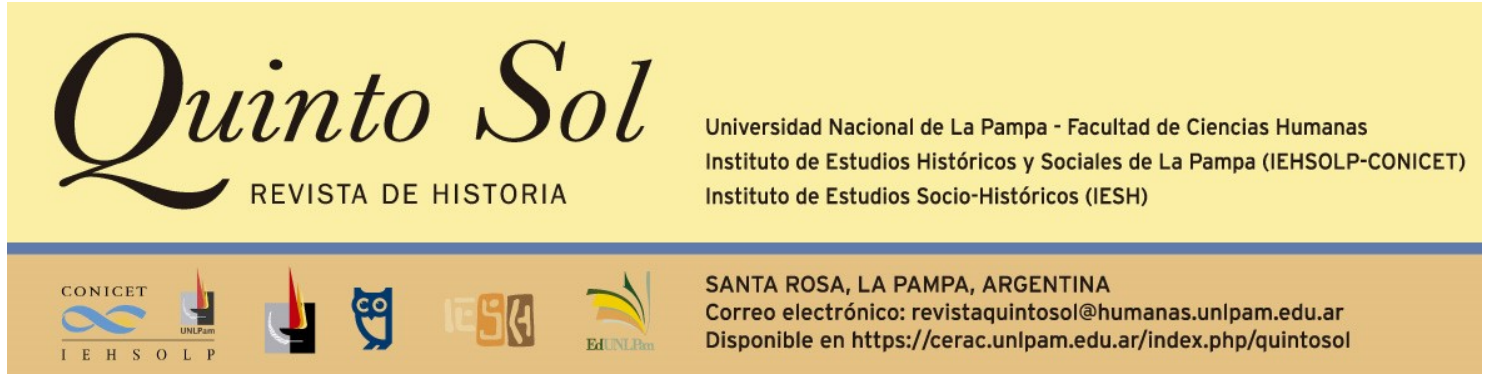

Quinto Sol, vol. 25, n 1, enero-abril 2021, ISSN 1851-2879, pp. 1-4

http://dx.doi.org/10.19137/qs.v25i1.4569

Esta obra se publica bajo licencia Creative Commons 4.0 Internacional. (Atribución-No ComercialCompartir lgual)

\title{
María Victoria Baratta. La Guerra del Paraguay y la construcción de la identidad nacional. SB, 2019, 288 páginas.
}

\section{Renzo Sanfilippo}

Consejo Nacional de Investigaciones Científicas y Técnicas

Universidad Nacional de Rosario. Instituto de Estudios Históricos, Económicos, Sociales e Internacionales (CONICET).

Correo electrónico: renzosanfilippo@gmail.com

La guerra que enfrentó a la Triple Alianza formada por Brasil, Argentina y Uruguay contra Paraguay constituye un problema que despierta cada vez mayor interés en el mundo de los historiadores. Tanto en los países que se enfrentaron en aquella contienda, como en otras partes del globo, asistimos desde la última década a una renovación de temas y enfoques ligados al conflicto. María Victoria Baratta se ha nutrido de ella y, a la vez, ha contribuido a generarla: su libro La Guerra del Paraguay y la construcción de la identidad nacional es una apuesta valiente, sustentada en un análisis crítico y documentado que desarma mitos y teorías conspirativas profundamente arraigadas en la sociedad argentina.

El trabajo recupera los resultados de su tesis doctoral defendida en el año 2013, bajo la dirección de Fabio Wasserman. En aquella ocasión se preocupó por establecer la relación entre la guerra como fenómeno histórico y la construcción de la identidad argentina, a partir del discurso de las elites letradas. En la obra que aquí reseñamos amplía el análisis con la incorporación de las representaciones de la cultura popular. Para cumplir los objetivos de su investigación, se apoyó en un contundente corpus de fuentes: diarios y periódicos de los países implicados en la Guerra del Paraguay (para 
Argentina toma tanto la prensa porteña como del resto de las provincias) y de Europa; documentos oficiales, institucionales, correspondencia, folletos, testimonios y relatos; Diarios de Sesiones de la Cámara de Diputados y de la Cámara de Senadores en Argentina; relatos de corresponsales de guerra, memorias y cantares populares.

Creemos, como señala Ignacio Telesca en el prólogo, que "no se entiende la guerra de la triple alianza solo comprendiendo el tema identitario"; aun así, constituye en nuestro país una forma novedosa de abordar el conflicto. Baratta parte del concepto de "comunidades imaginadas" de Benedict Anderson (1983) y lo cruza con el de "guerra decimonónica" -referenciado en distintos autores como Tilly (1993), Rabinovich y Zubizarreta (2013)-, para afirmar que la Guerra del Paraguay fue un momento clave en la formación y transformación de los Estados nacionales que se enfrentaron. Para la autora, en Argentina constituyó la oportunidad de acallar disidencias internas, ligadas a las identidades partidarias. Liberales (mitristas o autonomistas) y federales -tanto en las elites letradas como en los soldados que combatieron en el frente-, apelaron desde la prensa, en las proclamas o en las coplas populares, a una identidad más amplia para defender sus distintas posiciones: una representación de la "nación argentina" cuyos atributos la distinguían de un "otro". Esta perspectiva es interesante porque incorpora los discursos identitarios que antes del conflicto ya circulaban en los países luego contendientes, así como las invenciones que derivaron de una política inestable de alianzas regionales.

Luego de introducir el problema, la autora estructura la obra en cinco capítulos. A continuación, presentaremos brevemente el argumento de cada uno de ellos y, hacia el final, puntualizaremos desde nuestra perspectiva cuáles son los aspectos más fuertes del libro y aquellos temas que quedaron por profundizar.

El primer capítulo ofrece una explicación sobre las causas del conflicto bélico, así como una descripción de su desarrollo y sus consecuencias políticas, económicas y sociales en los países que se enfrentaron. Respecto a las primeras, ubica la raíz en el proceso independentista en el continente, ya que junto a las nuevas soberanías en disputa surgieron constantes querellas por los límites territoriales. La Guerra de la Triple Alianza constituyó una oportunidad de dirimirlas. El argumento está en sintonía con la periodización que propone: al extender su estudio desde 1864 hasta 1876, le otorga importancia a la ocupación que mantuvieron Argentina y Brasil -que no cedían en sus pretensiones territoriales- sobre Paraguay, luego de 1870. También a la decisión de incorporar el Tratado Secreto de la Triple Alianza como único anexo documental. Respecto a las consecuencias, sostiene que fueron diversas para los países beligerantes: la economía y la sociedad paraguaya quedaron diezmadas, el Imperio de Brasil entró en crisis, Uruguay no reclamó nuevos territorios y el Estado nacional argentino resultó el "gran vencedor" al acallar disidencias internas y recibir un impulso económico.

El segundo capítulo es el más extenso, lo cual se explica porque allí reside la cuestión nodal del libro: vale recordar, el rol que jugó la Guerra del Paraguay en la definición de la identidad argentina. La hipótesis de la autora es que, tanto desde el gobierno nacional y sus apoyos provinciales, como desde la oposición en sus distintas variantes, se apeló discursivamente a la existencia de una nación argentina para justificar posiciones. El apoyo o el rechazo a la Guerra, la representación del conflicto y sus actores, encontró en la identidad nacional un sustento que, a su vez, contribuyó a proveer un recurso simbólico al Estado en formación. Esto no quiere decir, para María Victoria Baratta, que la identidad argentina haya barrido otras como la americana, la 
federal o la provincial $y$, de hecho, su efectividad parece haber sido conflictiva durante las etapas de reclutamiento. Sin embargo, sostiene que las referencias a una nación de raíz político-pactista pueden rastrearse en los discursos letrados de diversa afinidad partidaria, así como en la cultura popular, y que el uso de símbolos como la bandera, el himno y la música militar fue un factor de cohesión en el frente de batalla. A su vez, esta hipótesis la llevó a renovar la mirada sobre acontecimientos como los Desbandes de Basualdo y Toledo, prestando atención a factores internos.

Los capítulos 3 y 4 pueden analizarse a partir de una premisa de la que parte la autora y que ha tenido un consenso historiográfico en distintas corrientes: la Guerra del Paraguay fue impopular en Argentina. Es decir, contó con apoyos y logró movilizar a una cantidad inédita de su población -apelando tanto a la cuestión identitaria como al uso de la fuerza- pero tuvo importantes resistencias. Estas se manifestaron a través de la prensa de identidad federal, en la pluma de Alberdi, en las representaciones sobre el Imperio de Brasil -cuya condena por monárquico y esclavócrata fue común a distintos partidos-, en los discursos pronunciados en el Congreso y en las deserciones. Ahora bien, ¿fue impopular por solidaridad con Paraguay, como han señalado diversos historiadores revisionistas? Su análisis de las fuentes la lleva hacia una respuesta en sentido contrario. Más allá del apoyo "paraguayista" de una parte de la sociedad correntina, parece haber primado tanto en Buenos Aires como en la mayoría de las provincias una caracterización negativa sobre Paraguay y su gobierno, considerado "tiránico". Por eso, la autora cree que para explicar la impopularidad de la Guerra hay que considerar otros factores como el proceso de concentración de la tierra y la represión estatal sobre los grupos menos favorecidos del mundo rural, la desconfianza que inspiraba Brasil como aliado y la duración de la contienda.

El capítulo 5 comienza con el análisis del rol que desempeñó Uruguay en el enfrentamiento, representado muchas veces en la historiografía referida a la Guerra del Paraguay como un "aliado simbólico" cuya acción no tuvo prácticamente consecuencias, pero para la autora fue crucial porque fue el espacio en el que comenzaron a tomar forma las tensiones y las alianzas regionales. Además, sostiene que esta experiencia trágica tuvo el efecto de terminar de consolidar su hasta entonces frágil independencia nacional. Luego, se dedica a desarmar las teorías conspirativas revisionistas- que surgieron en Argentina a partir de la década de 1950 y que parecen haber obtenido un amplio consenso en la sociedad. Como marca Baratta, la mayoría de estos relatos se basan en un supuesto: las causas, el desarrollo y las consecuencias de la Guerra del Paraguay se explican por la "conspiración británica". Ofrecen, de esta manera, una "exculpación" que encuentra los males en un enemigo exterior y evita indagar en las responsabilidades de los actores regionales. Sin embargo, la autora señala que en la comunidad científica este tipo de explicaciones vienen siendo rechazadas desde la década del ochenta y existe ya una importante cantidad de trabajos que demuestran que el desarrollo industrial de Paraguay al momento de iniciarse la contienda era bastante modesto y que, inclusive, el vínculo comercial con Gran Bretaña había sido favorecido por los gobiernos de Carlos Antonio López y después por su hijo Francisco Solano López.

En el balance total de La Guerra del Paraguay y la construcción de la identidad nacional nos queda una sensación de desequilibrio entre la importancia atribuida a los discursos identitarios de las elites y la voz de los sectores populares. La intención de incorporar la postura de estos últimos durante el conflicto es meritoria, pero creemos 
que es un aspecto que se puede trabajar con mayor profundidad. Por otro lado, las diversas funciones que desempeñaron las mujeres durante el conflicto, el tráfico de niños paraguayos entre los países aliados, las consecuencias que tuvo la Guerra sobre la disolución o permanencia de la identidad federal en las distintas provincias argentinas y la memoria de los ex combatientes en las décadas que siguieron al enfrentamiento, se vislumbran como líneas temáticas a explorar en el futuro, varias de ellas señaladas por la propia autora.

Ahora bien, creemos apropiado finalizar la reseña enfatizando dos aspectos que se suman al original aporte que constituye el trabajo en cuestión, enriquecedores para el porvenir. En primer lugar, destacar la valentía de avanzar y no detenerse frente a cuestiones morales que suelen aparecer al estudiar una Guerra que se llevó la vida de miles de personas. Sólo la investigación -facilitada en este caso por la distancia temporal- puede aportarnos herramientas para comprender mejor el cómo y el porqué de la tragedia. El conflicto fue americano y las responsabilidades fueron compartidas; la autora no teme a explicitar su visión sobre las mismas. En segundo lugar, rescatamos el lenguaje sencillo y directo de la obra, que la torna accesible para su lectura en diferentes espacios y con distintos públicos. En un gesto que no sobra en la comunidad académica, María Victoria Baratta nos ofrece una lectura amena sin resignar un ápice de la seriedad necesaria para estudiar un proceso histórico complejo como fue la Guerra del Paraguay.

\section{Referencias bibliográficas}

1. Anderson, B. (1983). Imaginary communities: reflections on the origin and spread of nationalism. Verso.

2. Rabinovich, A. y Zubizarreta, I. (2013). Clausewitz a caballo, o hacia una teoría de la guerra y la política aplicada al Río de la Plata. Foros de Historia PolíticaPrograma Interuniversitario de Historia Política.

3. Tilly, Ch. (1993). European Revolutions, 1492-1992. Blackwell. 